\title{
1 What is a gesture? A meaning-based approach to defining gestural
}

\section{2 repertoires}

3

4 Catherine Hobaiter* and Richard W. Byrne

5

6

7 School of Psychology and Neuroscience, University of St Andrews, St Andrews, KY16

8 9JP, Scotland

9

10 *Correspondence: C Hobaiter, School of Psychology and Neuroscience, University of

11 St Andrews, St Andrews, Scotland.

12 E-mail: clh42@st-andrews.ac.uk

13 Fax: +44 (0) 1334463042 


\section{Abstract}

15 Current systems of categorizing ape gestures are typically subjective, relying on human

16 intuition. We have systematized the features on which categorization depends

17 (movement; body part; one/both limbs; use of detached object; rhythmic repetition;

18 contact with recipient), showing that a potential repertoire of over 1000 gestures is

19 physically possible, as large as the lexicon of some languages. In contrast, little more than

20 a tenth of these gestures is used in chimpanzee communication. The striking overlaps in

21 repertoire found between populations and even species of great ape are evidently not a

22 result of a restricted set of possible gestures. Using the reactions of signallers to identify

23 which gestures are intended to be different by the apes themselves, we revised the current

24 classification, making some new distinctions and abolishing others previously considered

25 important, giving a final repertoire of 81. A small number of gestures are used deictically,

26 such that the recipient must pay attention to specific locations to satisfy the signaller;

27 raising the possibility of a stepping-stone to the evolution of reference.

29 Keywords

30 communication; Pan; intentional gesture; repertoire; deixis 


\section{$31 \quad$ Highlights}

32 - We provide a meaning-based categorization of the chimpanzee gestural repertoire

33 - Chimpanzees could employ over 1000 gestures, but only use $12 \%$ of these.

34 - We use signaller reactions to identify features salient in determining meaning.

35 - A sub-set of gesture types is employed deictically to refer to external locations.

\section{1. Introduction}

38 All great apes, including humans, employ a rich range of communicative signals that

39 includes facial expressions, body postures, vocalizations, and gestures. Gestures were

40 described among the first field studies of great apes by Goodall (1968), Schaller (1963),

41 Nishida (1980), and Plooij (1978); but it was more recent work (Tomasello et al., 1985,

42 1989, 1994; Leavens et al., 1996; Leavens \& Hopkins, 1998) that highlighted that, unlike

43 many animal signals, chimpanzee gestures are used intentionally. That is, they are used

44 towards a specific recipient and with a particular goal in the signaller's mind. From these

45 captive studies of chimpanzees, the field expanded to include all four non-human ape

46 species (bonobo: Pika et al., 2005; gorilla: Tanner \& Byrne; 1996, Pika et al. 2003; Genty

47 et al., 2009; and orang-utan: Liebal et al., 2006; Cartmill \& Byrne, 2007), as well as the

48 first studies in the wild of gestural catalogues (chimpanzees: Hobaiter \& Byrne, 2011a,

49 2011b; gorillas: Genty et al., 2009).

51 But what is a gesture? In the 21-years since Tomasello et al.'s 1985 chimpanzee paper the

52 field has exploded: a Google scholar search returns 273 articles on nonhuman primate

53 gesture published between 1985-2016. Some areas of the field remain remarkably 
54 consistent: for example, there is broad agreement that a gesture should be a physical

55 movement that is not mechanically effective, and definition should incorporate a measure

56 of the signaller's intention to communicate (Tomasello et al., 1985; Pika et al., 2005;

57 Liebal et al., 2006; Tanner \& Byrne, 1993; Genty et al., 2009; Hobaiter \& Byrne, 2011a;

58 Roberts et al., 2012, 2014; Frohlich et al., 2016). After that, the consensus starts to

59 crumble. Should gestures be physical movements of the hand and fingers only (Leavens

60 \& Hopkins, 1998; Leavens et al,. 2010; Pollick \& De Waal, 2007; Roberts et al., 2012,

61 2014); could they include movements of the head (e.g. Tanner \& Byrne, 1996), body

62 postures (e.g. Genty et al., 2009), or facial movements (Cartmill \& Byrne, 2007). Given

63 their use as communicative signals it is particularly worrying that there is little agreement

64 on how we should discriminate one gesture from another. Even within a narrow

65 definition focused on hand and finger movements, is a reach with the palm up the same

66 as a reach with the palm down? How do we parse out the variation that results from a

67 change in the signaller's body posture (standing or sitting), or from their environment

68 (e.g. arboreal versus terrestrial), from the variation that results from the ape deliberately

69 encoding differences - perhaps subtly - in information? Frequency of observation may

70 impact a researcher's choice of whether to distinguish a gesture as a specific form, which

71 is problematic, since a gesture may be rare because the context in which it is typically

72 used is rare yet have a distinct meaning that is biologically important (e.g. gestures used

73 in consortship see Hobaiter \& Byrne, 2012).

74

75 The result of these ambiguities has been a field with a wide range of different gestural

76 repertoires, split to varying levels (c.f. Genty et al., 2009 with Hobaiter \& Byrne 2011a). 
77 Typically the approach has been to group by the morphological features that we, as

78 human observers, see as salient. For example: in our 2011 catalogue of chimpanzee

79 gestures (Hobaiter \& Byrne, 2011a) we distinguished arm shake (small repeated back and

80 forth motion of the arm), hand shake (repeated back and forth movement of the hand

81 from the wrist), and feet shake (repeated back and forth movement of the feet from the

82 ankles), on the basis of the body parts involved; but we lumped shaking with one arm or

83 shaking with both arms as being part of essentially the same gesture, arm shake. Perhaps

84 because humans are themselves great apes, this subjective approach has been quite

85 productive. However, the categorisations remain arbitrary, and the level of splitting has at

86 times been inconsistent (for example: we differentiated arm shake and hand shake, but

87 described the single gesture arm raise as including raise either the arm or the hand;

88 Hobaiter \& Byrne, 2011a). Indeed, whether the body part that was employed in

89 performing the movement formed part of a gesture's definition at all was not consistent

90 (for example: arm shake was distinguished from hand shake and leg shake by virtue of

91 the body part, but hand beckon was not distinguished from arm beckon or even, feasibly,

92 leg beckon; instead, beckon was defined only by the movement performed, irrespective of

93 body part; Hobaiter \& Byrne, 2011a). As a result, on paper, there appeared to be little

94 systematic consistency in how to define a gesture, or to distinguish what might represent

95 a new gesture type, rather than a variant of the same gesture.

97 Since great ape gestures are meaningful, it might be that a more relevant categorisation of

98 signals could be provided by considering their usage from the signaller's perspective. For

99 example: does any shaking movement, irrespective of the type or number of limbs 
100 involved, consistently convey the same intended meaning? We use the term 'meaning'

101 deliberately. Many systems of animal communication involve the transfer of detailed

102 information: for example, primate alarm calls may encode not only the type of predator,

103 but also the level of risk (Schlenker et al., 2016a) or its location (Cäsar et al., 2013;

104 Schlenker et al., 2016b). Assessing the effect of a signal on a recipient is sufficient to

105 assess information transfer. Whether the signaller intends to achieve this effect on

106 signaller behaviour remains unknown, and thought frequently not to be the case (Seyfarth

$107 \&$ Cheney, 2003). Great ape gesture is different, because it is intentional. Signallers select

108 their gestures based on a specific recipient and its state of attention; they pause and wait

109 for a response; and - where unsuccessful - persist in signalling until they have achieved

110 the desired change in recipient behaviour. In doing so great apes meet the criteria for $1^{\text {st }}$

111 order intentional communication (Dennett, 1987). There is evidence for the $1^{\text {st }}$ order

112 intentional (hereafter intentional) use of one or two signal types in a very few non-ape

113 species (e.g. grouper: Vail et al., 2013; macaque: Gupta \& Sinha, 2016), but compare this

114 with the extensive body of evidence for the intentional use of a large repertoire of

115 gestures within all ape species in both captivity (chimpanzee: Tomasello et al., 1985,

116 1989, 1994; Halina et al., 2013; bonobo: Pika et al., 2005; gorilla: Tanner \& Byrne; 1996,

117 Pika et al. 2003; Genty et al., 2009; and orang-utan: Liebal et al., 2006; Cartmill \&

118 Byrne, 2007) and the wild (chimpanzee: Hobaiter \& Byrne, 2011a,b, 2012, 2014; Roberts

119 et al., 2012, 2014; bonobo: Graham et al., 2016). This large data set of intentional non-

120 human signal use provides us with a unique opportunity: we are able to ask what a great

121 ape gesture 'means' in a human language-like sense (Grice, 1957; Hobaiter \& Byrne,

122 2014; Moore, 2016; although c.f. Scott-Phillips, 2015, 2016). 
124 To assess a signaller's intended meaning we must move beyond examining recipient

125 response, and consider signaller behaviour. A signaller's intended meaning is an internal

126 mental state, unavailable to external observers. To overcome this problem, we focus on

127 what behavioural response by the recipient appears to satisfy the signaller. This response

128 must both represent a plausible desire on the part of the signaller (thus, we exclude

129 agonistic behavioural responses from the recipient that targeted the signaller; 'attack me'

130 or 'chase me aggressively' are implausible desires), and lead to the cessation of

131 communication (Cartmill \& Byrne, 2010; Hobaiter \& Byrne, 2014).

133 Here we re-examine the gestural repertoire of the wild chimpanzee population of

134 Budongo forest, Uganda, using intended meaning as well as physical form to categorize

135 ape gestural signals. In linguistics 'distinctive features' represent the smallest unit of

136 variation used to describe the structure of phonemes. We adopt a similarly systematic

137 approach, using physical features within dimensions of variation in gesture morphology

138 (for example: the type of movement made, whether it is repeated in a rhythmic fashion,

139 and the body part involved) to define the potential repertoire of gestures (see Forrester,

1402008 and Roberts et al., 2012 for similar morphological categorisations of gesture,

141 focusing on body posture and limb and hand movements). We compare this with our own

142 research group's existing chimpanzee catalogue, which has been split at both a low level

143 that focused on movements and body areas (St Andrews Catalogue Short List: StAC_SL,

144 based on the level of splitting seen in the 66 gestures identified in Hobaiter \& Byrne,

145 2011a) and at a higher level that distinguishes, for example, hand versus arm use, and one 
$146 \operatorname{limb}$ (hand) versus two limb (hands) forms of the same gesture types (St Andrews

147 Catalogue Long List: StAC_LL shown in the Sonso specific column of Table 1, Hobaiter 148 \& Byrne 2011a).

149

150 We then use evidence from the signaller's intended meaning, to explore which of the

151 potential and actual distinctions have any communicative significance from a

152 chimpanzee's perspective, and thus generate a systematic categorisation of chimpanzee 153 gesture types.

\section{2. Methods}

\section{$157 \quad 2.1$ Ethical statement}

158 This was a purely observational study that did not contain any interventions. All research

159 adhered to the ethical ASAB/ABS Guidelines for the Use of Animals in Research and

160 was conducted in compliance with the applicable national laws (UNCST research permit:

161 NS179).

162

\section{$163 \quad 2.2$ Procedure}

164 All observations analysed here were made on habituated wild chimpanzees (Pan

165 troglodytes schweinfurthii), during field periods between 2007 and 2013 (see Hobaiter \&

166 Byrne, 2011a,b, 2012, 2014). The Sonso chimpanzee community at the Budongo

167 Conservation Field Station, in the Budongo Forest Reserve, Uganda consisted of 81 
168 individuals at the start of data collection. We used focal behaviour sampling (Altmann,

169 1974), filming all cases of gestural communication using a Sony Handycam.

171 We defined gestures as discrete, mechanically ineffective physical movements of the

172 body observed during intentional communication (see: Hobaiter \& Byrne, 2011a; 2014).

173 Our criterion of intentionality (at least $1^{\text {st }}$ order intentional use) was applied at the level of

174 the gesture instance, not the gesture type: thus, for every instance of gesture analysed, we

175 had evidence that the signaller gestured with the intention of changing the recipient's

176 behaviour, as indicated by one or more of response waiting, audience checking, and/or

177 persistence in communication (see Hobaiter \& Byrne 2011a, 2014 for a detailed

178 description of the methods used to assess intentional communication). The resulting data

179 set included 4535 individual gestures from 72 individuals. Our original catalogue

180 contained 66 gesture types, on the basis of gesture morphology, used to achieve 19

181 distinct meanings (Hobaiter \& Byrne, 2011a, 2014). In the present analysis, we included

1828 additional gesture types. Four were observed during the original field study, but at that

183 time we lacked evidence for intentional use in the Budongo community, which is now

184 available (field observations between 2011 and 2013): bipedal rocking; bipedal stance;

185 rocking, and thrust. Four were created by splitting two previously lumped gesture types:

186 present genitals backwards, present genitals forwards (formerly combined as present

187 sexual), reach palm, reach wrist (formerly combined as reach).

189 We investigated signallers' intended meaning through analysis of Apparently Satisfactory

190 Outcomes (ASOs; see: Cartmill \& Byrne 2009; Hobaiter \& Byrne, 2014). An ASO is an 
191 observable change in the recipient that apparently stops the signaller from signalling; an

192 ASO must conform to some plausible biological function for the signaller. Where we

193 found consistent patterns of use over multiple cases of communication, we used these as

194 an empirical indication of what signaller's intend to mean by giving the gesture.

195 (Typically, we required at least three cases from at least three signallers; where that was

196 not the case the data are clearly indicated; see Hobaiter \& Byrne, 2014 for a more

197 detailed description of methods used to analyse meaning.)

199 Play represents a prolific context for gestural communication and all data, including play

200 data, were used in morphological categorization of the gestures. However, signals given

201 during play are not necessarily used with their non-play, 'real world' meaning; and

202 outcomes within play may not reliably signal the gesture's meaning in a non-play context

203 (Bateson, 1972/1955; Bekoff \& Byres, 1981; Hobaiter \& Byrne, 2014). In order to

204 investigate the normal meaning of gestures we excluded gestural communication during

205 play from analyses of intended meaning (as per Hobaiter \& Byrne, 2014; gestures with a

206 play-related ASO represented 49.2\% individual gesture cases). We specified in each case

207 where an analysis was conducted on data from communication that occurred outside of

208 play. In addition, as our previous research has shown no effect of individual identity on

209 gestural meaning (Hobaiter \& Byrne, 2014), in the following analyses we combined

210 individual data. Parametric analyses were carried out in SPSS v11, non-parametric

211 analyses were calculated by hand, $\alpha=0.05$ was required for significance. Means are

212 given \pm standard deviation, throughout. All statistical tests were two-tailed. 
214 Table 1. Classification features for splitting gestures. The six initial features used to 215 describe each gesture type within the catalogue; a value must be recorded for each feature 216 in order to identify the specific gesture form (see Table S1).

\begin{tabular}{|lll|}
\hline $\begin{array}{l}\text { Feature } \\
(\mathbf{n}=\mathbf{v a l u e s})\end{array}$ & Definition & Possible values \\
\hline Movement (36) & $\begin{array}{l}\text { The physical movement of the } \\
\text { gesture type. }\end{array}$ & $\begin{array}{l}\text { Bend; bite; clap; cover; dangle; } \\
\text { embrace; fling; grab; grab hold; grab } \\
\text { pull; hit; jump; locomote; Look; } \\
\text { move object; offer; posture; posture } \\
\text { bipedal; push; raise; reach; rock; roll } \\
\text { over; rub; scratch; shake*; shake } \\
\text { object*; spin; splash; stroke; swing; } \\
\text { tear off; throw; touch; touch hold; } \\
\text { wave }\end{array}$ \\
\hline Body part (11) & $\begin{array}{l}\text { The area moved while } \\
\text { gesturing. Unless specified in } \\
\text { the analysis these terms include } \\
\text { the use of both single and } \\
\text { double-limbs; e.g. body part } \\
\text { hand refers to the use of either } \\
\text { one hand or two hands. }\end{array}$ & $\begin{array}{l}\text { Arm; body; fingers; foot; genitals; } \\
\text { rump }\end{array}$ \\
\hline $\begin{array}{l}\text { Single/Double } \\
\text { limb (2) }\end{array}$ & $\begin{array}{l}\text { Where gestures involved } \\
\text { movements of the limbs were } \\
\text { one or both involved }\end{array}$ & Single; double \\
\hline $\begin{array}{l}\text { Detached object } \\
\text { use (2) }\end{array}$ & $\begin{array}{l}\text { Use of a detached object by the } \\
\text { body part gesturing. }\end{array}$ & Yes; no \\
\hline $\begin{array}{l}\text { Rhythmic } \\
\text { repetition (2) }\end{array}$ & $\begin{array}{l}\text { A repetitive movement is } \\
\text { produced with a regularly } \\
\text { spaced rhythm indicating it is } \\
\text { part of a single continuous } \\
\text { gesture e.g. tapping }\end{array}$ & Yes; no \\
\hline $\begin{array}{l}\text { The movement of the gesture } \\
\text { requires physical contact with } \\
\text { the recipient }\end{array}$ & Yes; no \\
\hline Contact (2) & & \\
\hline
\end{tabular}

* The distinction between a shake movement + detached object use, and a shake object 219 movement, is that in shake the focus of the movement is to shake the limb; whereas in 220 shake object the focus of the movement is to shake an object that remains attached (for example a sapling or branch). 


\section{Results}

\section{$227 \quad 3.1$ Initial Classification}

228 Six features have regularly been used, in our own and other studies of great ape

229 communication and behaviour, to describe and categorize gestures in their repertoire (e.g.

230 Cartmill \& Byrne, 2007, 2010; Genty et al., 2009; Graham et al., 2016; Goodall, 1968;

231 Halina et al., 2013; Hobaiter \& Byrne, 2011a, 2014; Hobaiter et al., 2013; Leavens \&

232 Hopkins, 1998; Leavens et al., 2010; Liebal et al., 2006; Pika et al., 2003, 2005; Plooij,

233 1978; Pollick \& DeWaal, 2007; Roberts et al., 2012; Schaller, 1963; Tanner \& Byrne,

234 1996; Tomasello et al., 1985, 1989, 1994). Together, these six features formed the basis

235 of our initial categorization (Table 1). The features were as follows: (1) movement

$236(\mathrm{n}=36)$. Where chimpanzees made two different movements at the same time with

237 different limbs, we treated them as two separate gestures produced together. Thus, if a

238 chimpanzee were observed to swing with one leg and shake with the other, we would

239 treat that as the movements of two separate gestures produced in tandem, rather than a

240 single gesture with a 'swing-shake' movement. (2) Body parts ( $\mathrm{n}=11)$; (3) single or

241 double limb (n=2); (4) detached object use (n=2); (5) rhythmic repetition of movement

$242(\mathrm{n}=2)$; and (6) contact with recipient $(\mathrm{n}=2)$. So, for example, the gesture: arm shake was

243 classified as [movement $=$ shake; body part $=$ arm; single $/$ double limb $=$ single; detached

244 object use $=$ no; rhythmic repetition $=$ yes; contact with recipient $=$ no]; the gesture drum

245 other was classified as [movement $=$ hit; body part $=$ hand; single $/$ double limb $=$ double;

246 detached object use $=$ no; rhythmic repetition $=$ yes; contact with recipient $=$ yes $]$; and the

247 gesture object in mouth was classified as [movement = offer; body part = mouth; 
248 single $/$ double $\operatorname{limb}=$ single; detached object use $=$ yes; rhythmic repetition $=$ no; contact

249 with recipient $=$ no].

251 By multiplying the possible values for each feature we constructed a matrix of the

252 hypothetical maximum repertoire size: $\mathrm{n}=6336$. However, this included a large number

253 of implausible options, for example: a beckon movement with the body part rump. We

254 therefore excluded (a) the option of double limb use where only one existed (e.g. body or

255 head); (b) the option of single limb use where the movement required two (e.g. clap); (c)

256 the option of detached object use where it could not be employed by the body part (e.g.

257 body, genitals); (d) impossible or physically improbable movement + body part

258 combinations (e.g. spin + head; or bite + hand). This process left us with a remaining

259 possible maximum repertoire size: $\mathrm{n}=1005$.

261 We then examined $n=4535$ cases of gesture use within our catalogue using the 6 features

262 described in Table 1 to assign each to one of the $n=1005$ possible gesture types. When

263 categorized using these features, chimpanzees showed an employed repertoire size:

$264 \mathrm{n}=124(12.3 \%$ of the maximum possible). So, for example, the chimpanzees showed the

265 movement shake with the body parts: $\operatorname{arm}(\mathrm{s})$, feet, hand(s), head, and leg(s) but not:

266 rump, genitals, or foot.

\section{3.2 Did the 6 initial features provided a sufficiently detailed categorization?}

269 At first sight, this new morphological classification resembles our existing chimpanzee

270 StAC long list, with a similar number of gesture types (StAC_LL $n=158)$. However, 
271 even within our short list (StAC_SL, n=72), a number of gesture types were lumped by

272 the new categorization. Lumped gestures could be grouped into three sets; we examined

273 each set individually, comparing the distribution of ASOs achieved for the newly lumped

274 gesture types to determine if it was appropriate to combine them or if, based on the use of

275 these gestures by the chimpanzees, we needed to specify additional features in our

276 classification system. The 6-feature morphological classification no longer distinguished

277 gestures:

278

279 (i) Where a movement of hitting is performed with both limbs and could be performed

280 either simultaneously or with alternating hits. For example: drum other (alternating hits),

281 is not distinct from slap other 2-hands multiple (simultaneous hits). Four such cases

282 occurred (Table 2): in each case, both alternating and simultaneous gestures were used

283 either exclusively in play or with three or fewer cases of use outside of play. Therefore,

284 we find no justification from the chimpanzee behaviour to distinguish simultaneous from

285 alternating hitting movements (Table 2) and so no requirement for an additional feature to

286 discriminate simultaneous from alternating hitting movements.

288 (ii) Where locomotion, posture, or spinning movements are performed with the body as a 289 whole. Three movement + body part combinations contained multiple gestures that were

290 split in our original classification but were lumped by the new classification using the 6

291 features: [locomotion + body] lumps the two gestures: gallop \& stiff walk; [posture +

292 body] lumps the gestures: bow \& head stand; and [spin + body] lumps the gestures:

293 pirouette, side roulade \& somersault). 
295 Only the movement spin with the body part body provided sufficient examples of use

296 outside of play for comparison, termed: side roulade $(\mathrm{n}=9)$ and somersault $(\mathrm{n}=15)$. In our

297 original classification these gesture forms differed in the position of the body when it was

298 spinning: extended out in side roulade, and curled up in somersault. However, the

299 specific position in which the body was held was not differentiated in our new

300 classification. As both gestures were used exclusively to achieve the ASO 'Stop that', we

301 found no justification from the chimpanzee behaviour to distinguish gestures that involve

302 the movement spin with the body (Table 2) and so no requirement for an additional

303 feature to discriminate the specific position in which the body part was held.

Table: 2 Gestures lumped by the 6-feature classification that were previously split in the StAC Long list.

\begin{tabular}{|ll|}
\hline $\begin{array}{l}\text { Gestures with simultaneous vs alternating } \\
\text { hitting movement }\end{array}$ & Locomotion and body posture gestures \\
\hline Kick 2-feet* \& stomp 2-feet other** & Gallop** \& stiff Walk*** \\
\hline Kick* \& stomp other * & Bow*** \& head stand* \\
\hline $\begin{array}{l}\text { Drum object** \& slap object, 2-handed } \\
\text { multiple*** }\end{array}$ & Pirouette** \& side roulade \& somersault \\
\hline Drum other** \& slap other, 2-handed multiple* \\
\hline$*$ ASO $=$ play related in all cases; $* *$ ASO $=3$ or fewer cases of gesture use outside of \\
play; $* * * 3$ or fewer cases of gesture use
\end{tabular}

311 (iii) Where the gestures differed in directing or not directing the recipient's behaviour.

312 We observed three cases of movement + body part combinations in which the difference

313 that had previously been used to split them can be described as the signaller intending to

314 direct the recipient's behaviour: in other words, not just 'Move away' but 'Move yourself 
315 there'. In each of the three cases we observed distinct differences in the distribution of

316 the ASOs achieved by the gestures that would be combined by the features approach

317 (Table 3). The gesture directed push performed with the fingers $(\mathrm{n}=26)$ was primarily

318 employed to achieve the ASO 'Reposition' $(\mathrm{n}=15)$; whereas the gesture poke $(\mathrm{n}=14)$ was

319 primarily employed in play $(\mathrm{n}=12)$. The gesture directed push performed with the hand

320 ( $\mathrm{n}=142$ ) was also primarily employed to achieve the ASO 'Reposition' ( $\mathrm{n}=73$ ); whereas

321 the gesture $p u s h(n=23)$ was primarily employed to achieve the ASO 'Stop that' $(n=14)$.

322 The gesture arm swing ( $\mathrm{n}=166)$ was primarily employed in play $(\mathrm{n}=139)$ and outside of

323 play ( $\mathrm{n}=27)$ was used to achieve the ASO of 'Follow' $(\mathrm{n}=16)$; whereas the gesture arm

324 swing directed $(\mathrm{n}=6)$ was primarily used to achieve the ASOs of 'Move closer' $(\mathrm{n}=3)$ and

325 'Follow' $(\mathrm{n}=2)$. 
Table: 3 Distribution of ASOs in gestures lumped by the 6-feature classification that were previously split in the StAC Long list. The proportion of gesture cases used to achieve an ASO is plotted for movements produced with or without directedness. ASOs with potentially similar meanings are plotted adjacent to each other. $\mathrm{ACQ}=$ 'Acquire object'; REP = 'Reposition'; CLM = 'Climb on me'; PLY = 'Play'; FLW = 'Follow'; TRA = 'Travel with me (adult)'; MVC = 'Move closer'; TRI = 'Travel with me (infant)'; MVA = 'Move away'; STP = 'Stop that'. For clarity only ASOs for which the gesture was employed are labelled.
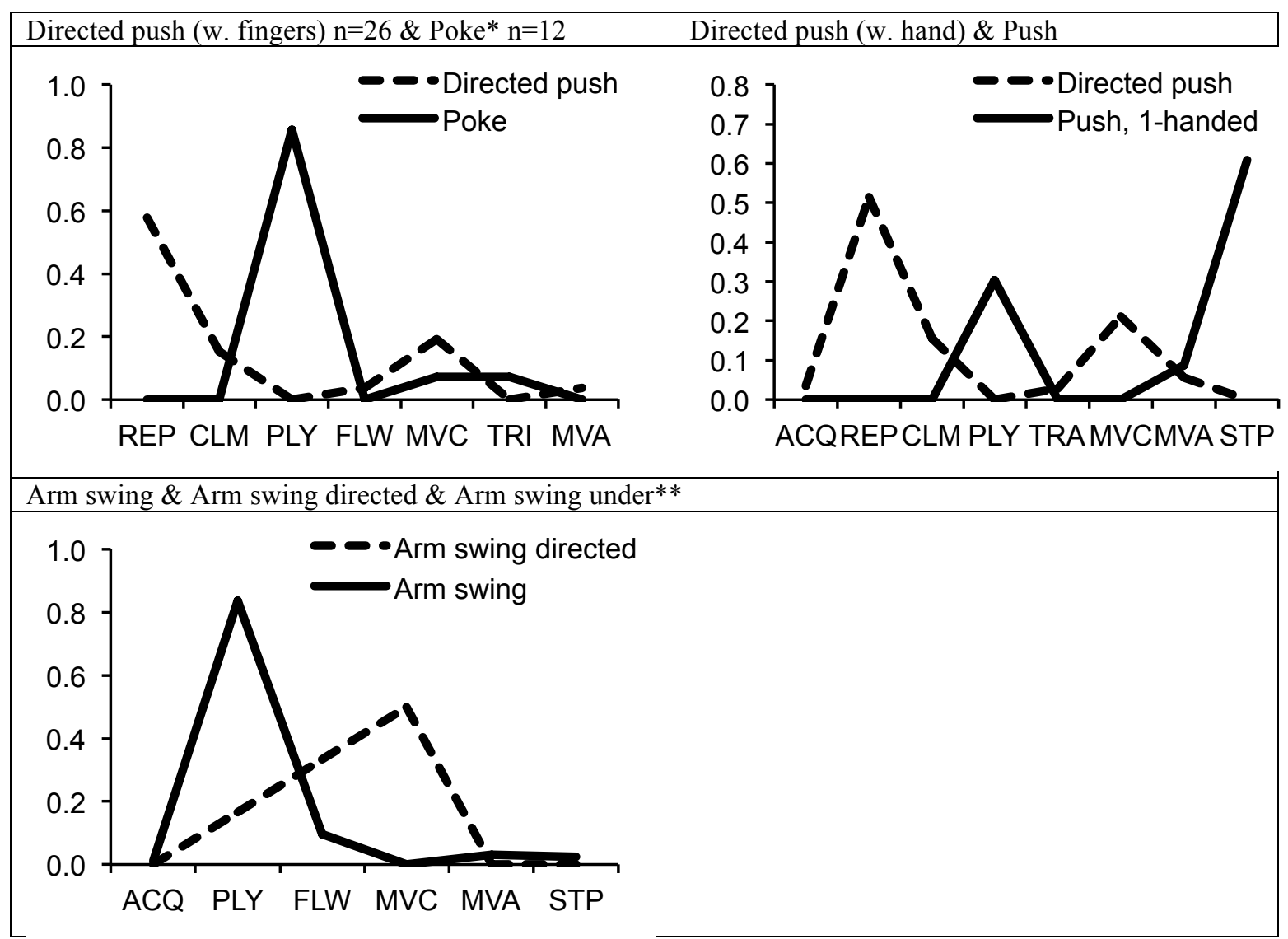

$* 3$ or fewer cases of gesture use outside of play; $* * 3$ or fewer cases of gesture use.

337 From these clear distinctions in use we suggest that there exists an additional element of

338 classification 'deixis'. Given its use across several movement + body part combinations

339 we consider this to be an additional feature that may categorize movements: Place

340 indicated. However, as deictic indication refers to a potentially infinite number of points

341 in the external environment it seems inappropriate to classify it as a specific physical

342 feature of the gesture in the same way as a body part, or use of an object. We therefore 
343 suggest deixis be recorded but treated separately from the physical features of a gesture.

344 We continue our current analysis focused on the six physical features previously defined.

346 3.3 Do the 6 physical features used to describe gestures in the repertoire modify the

$347 \quad$ meaning of the gestures?

348 Here we describe the forms of the gestures used, and then employ the ASOs achieved

349 outside of play to investigate whether the chimpanzees distinguish different meanings

350 from the physical features (Table 1) that might modify the feature movement.

351

352 3.3.1 Does varying the body part with which a movement is performed modify the

353 meaning of a gesture?

354 Of the 11 body parts, the hand was the most commonly employed in gesturing and was

355 used to perform the greatest range of movements (Table 4); together the hand, fingers,

356 and knuckles account for over half of all gestures produced $(n=2678)$.

358 Table 4. Number of gesture instances and movement types per body part.

\begin{tabular}{|lll|}
\hline Body part & Instances; $n$ & Movements; \\
\hline Mouth & 114 & 4 \\
\hline Head & 30 & 4 \\
\hline Arm & 316 & 9 \\
\hline Hand & 1991 & 17 \\
\hline Fingers & 533 & 6 \\
\hline Knuckles & 154 & 4 \\
\hline Body & 540 & 10 \\
\hline Rump & 32 & 1 \\
\hline Genitals & 201 & 2 \\
\hline Leg & 26 & 3 \\
\hline Foot & 416 & 7 \\
\hline
\end{tabular}


361 The majority of movements (22/36) were performed by only a single body part: for

362 example, clap was performed only with the hands whereas rub was performed only with

363 the rump. Six movements were performed with two body parts, and eight with three or

364 more (body parts per movement: range $=1-6$; mean $=1.9 \pm 1.5$ ). When we excluded

365 gesture cases that were (a) used during play, (b) with an ASO of unknown, or (c) where

366 there were fewer than three examples of the specific movement + body part combination,

367 the range of body parts per movement decreased (movements performed by a single body

368 part $=18 / 26$; body parts per movement: range $=1-4$, mean $=1.5 \pm 0.9)$.

369

370 For the eight movements expressed using more than one body part we examined the

371 pattern of ASOs achieved in non-play situations on a case-by-case basis. A visual

372 inspection of Table 5 shows several cases of clear variation between the distribution of

373 ASOs achieved by different body parts with the same movement, suggesting that

374 chimpanzees attended to both the movement and body part when decoding the signaller's

375 intended meaning.

376

377

378

379

380

381

382 
Table 5. Distribution of ASOs produced by different body parts within a movement. The proportion of gesture cases used to achieve an ASO is plotted for the same movement produced with different body parts. ASOs with potentially similar meanings are plotted adjacent to each other. $\mathrm{ACQ}=$ 'Acquire object'; DIR = 'Direction attention'; $\mathrm{GRM}=$ 'Groom'; REP = 'Reposition'; $\mathrm{CLM}=$ 'Climb on me'; CLY = 'Climb on you'; $\mathrm{SXF}=$ 'Sexual attention to female'; SXM = 'Sexual attention to male'; FLW = 'Follow'; TRA = 'Travel with me (adult)'; MVC = 'Move closer'; CNT = 'Contact'; TRI = 'Travel with me (infant)'; MVA = 'Move away'; STP = 'Stop that'. For clarity only ASOs for which the gesture was employed are labelled.

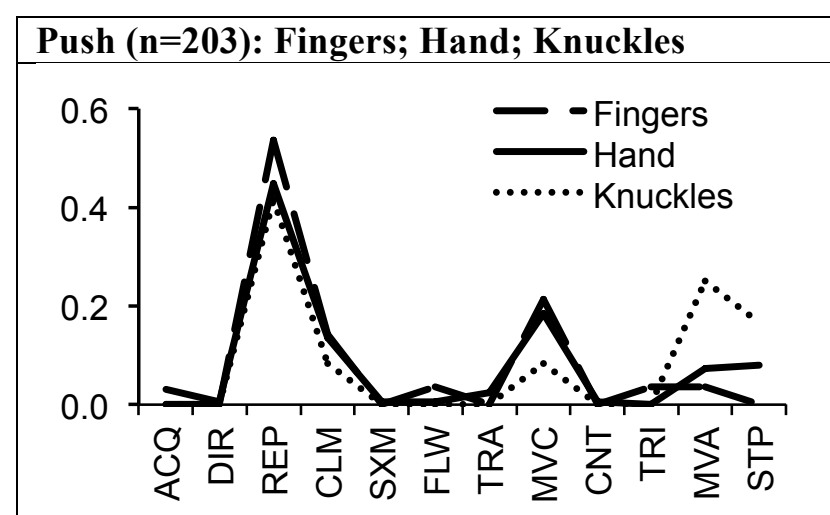

\section{Fling ( $n=52)$ : Hand; Arm}

Shake (n=13): Arm; Hand
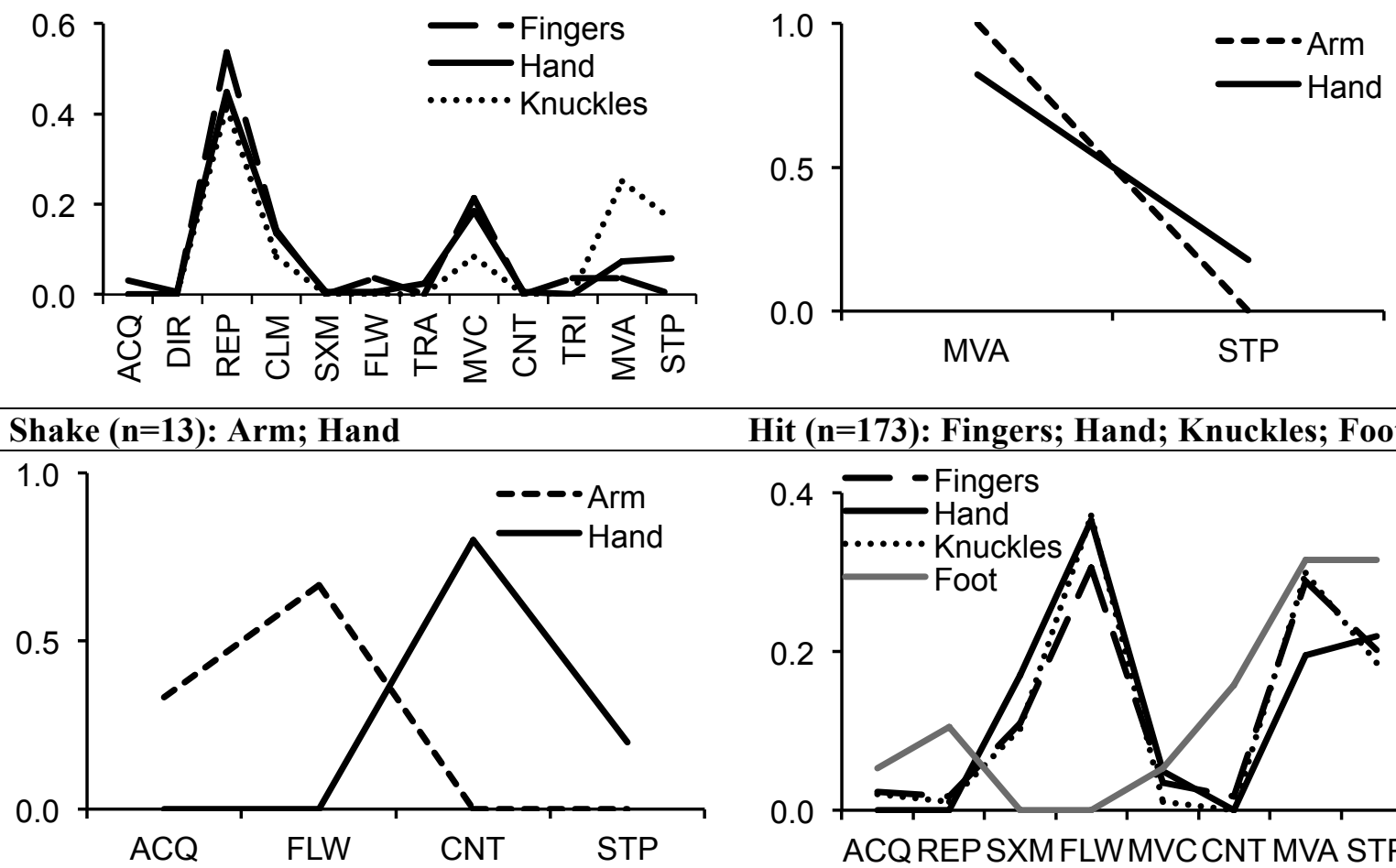

Hit (n=173): Fingers; Hand; Knuckles; Foot

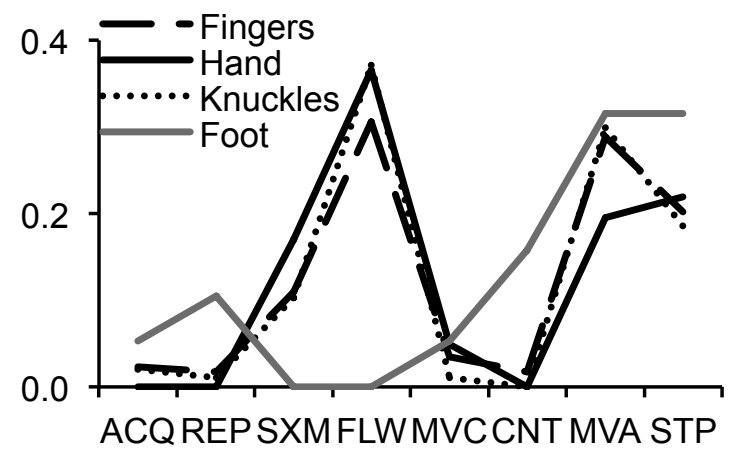

\section{Touch $(n=64)$ : Fingers; Hand}

Offer (n=190): Arm; Body; Feet; Genitals
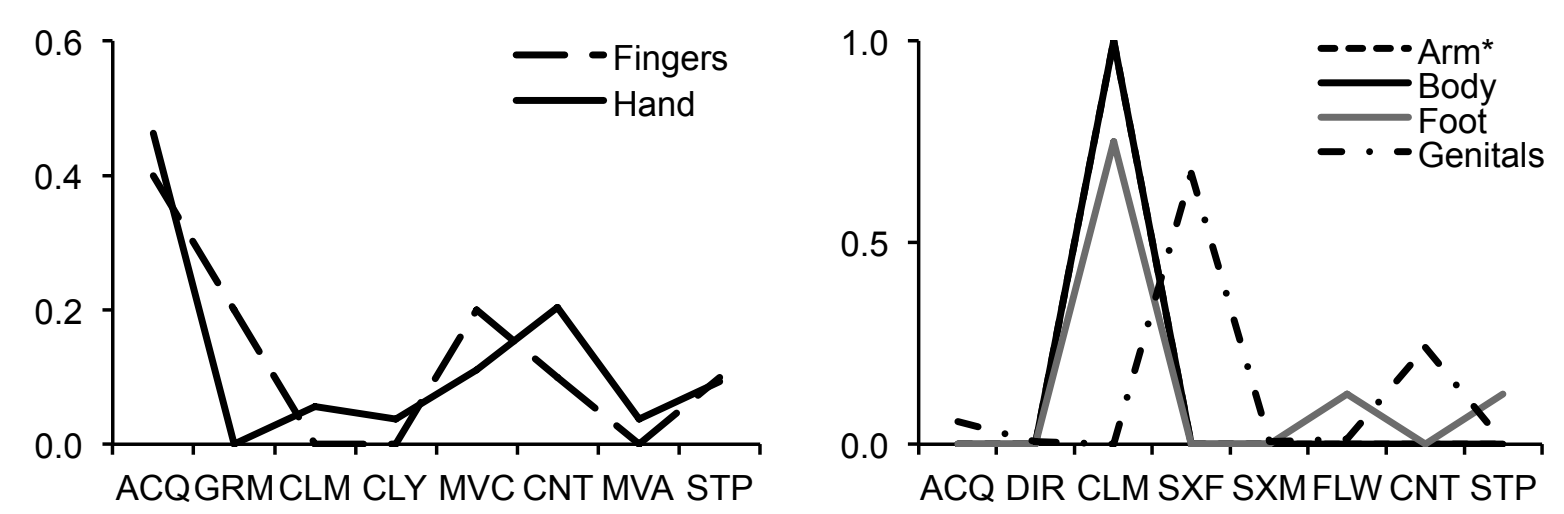

* Arm and Body have identical distributions 


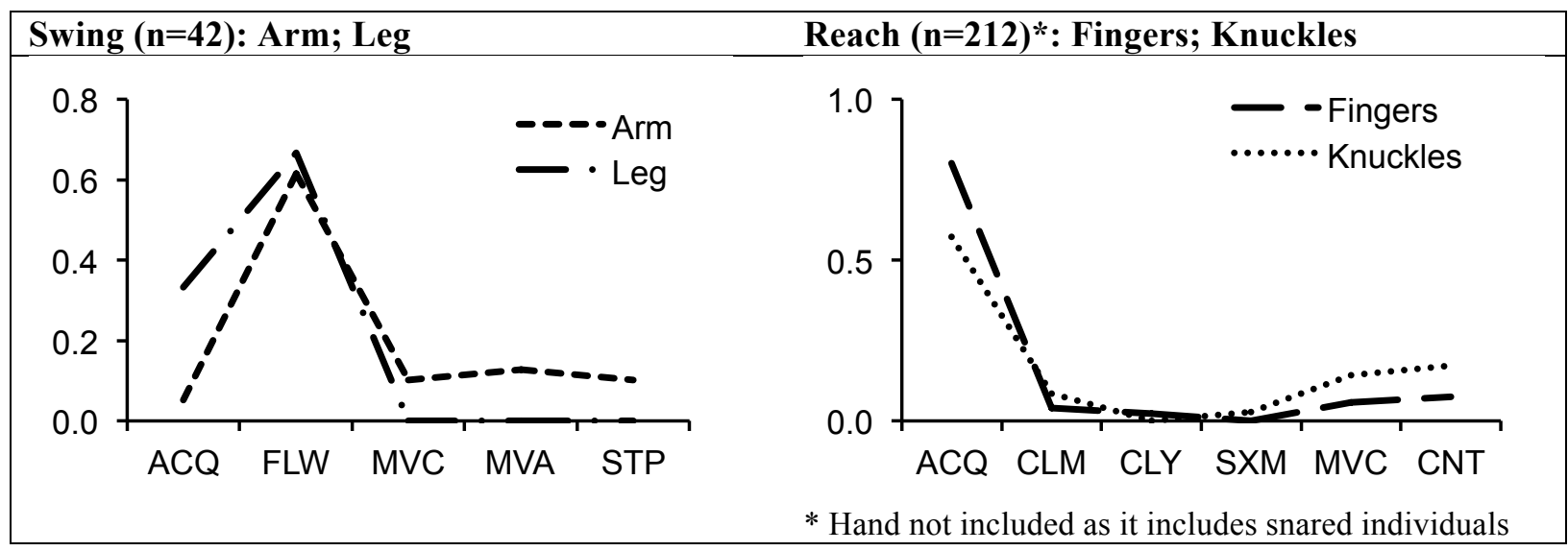

394

395 For three movements, fling, swing, and reach the pattern of distributions between the

396 body parts was very similar. Regardless of body parts, the movement fling achieved a

397 primary ASO 'Move away' ( $>80 \%$ of use); the movement swing achieved a primary

398 ASO 'Follow' ( $>60 \%$ of use); and the movement reach achieved a primary ASO

399 'Acquire object' ( $>50 \%$ of use). In the case of reach there was a difference between the

400 frequency with which the primary ASO was achieved by the fingers $(80 \%)$ or the

401 knuckles (57\%), with the latter often used to achieve secondary ASOs such as the

402 affiliative 'Contact'. Similarly, in the case of the movements push, hit, touch, and offer,

403 the ASO patterns suggested only minor variation between the different parts of the hand,

404 in particular the knuckles from the hand and fingers, and more substantial discrimination

405 between these and other body parts such as the feet or genitals. In push and touch all

406 body parts achieved the same primary ASO ('Reposition' and 'Acquire object'

407 respectively) with minor variation in the patterns of secondary ASOs (see for example:

408 push with knuckles to achieve 'Move Away').

409

410 The two movements hit and offer showed more substantial variation, with different body

411 parts achieving different primary ASOs. In the case of hit, the primary ASO for fingers, 
412 hand, and knuckles was 'Follow'; whereas hit with the feet gave joint primary ASOs of

413 'Move away' and 'Stop that'. Interestingly, this suggests that in non-play situations

414 chimpanzees make little distinction between a Slap gesture (typically hands or fingers)

415 and a Punch gesture (typically knuckles); but do discriminate these from foot based

416 Stomp gestures.

418 With the movement offer, the primary ASO for arm, body, or leg was 'Climb on me',

419 whereas for the genitals it was a request for 'Sexual Attention'. However, a large

420 category of the movement offer was excluded from these analyses: the gesture present

421 groom $(\mathrm{n}=181)$, which is almost exclusively employed for the ASO 'Direct attention'

$422(\mathrm{n}=177)$. In present groom gestures the body part offered was typically not specified in

423 coding leading to these cases being excluded as both movement and body part were

424 required for this analysis. In both present groom and present climb on me the movement

425 indicates a specific location, in this case on the signaller's body. The distinction in

426 meaning between these offer movements is seen not in the body part offered (in both

427 present groom and present climb on me the foot or back could be offered). Instead the

428 distinction in meaning was identified from the recipient's behaviour (gesturing by the

429 signaller stops when the recipient either (a) starts to groom in the specified location or

430 moves existing grooming activity to that location, or (b) climbs on the signaller). As a

431 result, the gestures present groom and present climb on me are now lumped as the single

432 gesture present. 
434 Finally, one movement - shake - showed near opposite patterns of distribution for the

435 two body parts: arm, used to achieve the primary ASO 'Follow', and hand, used to

436 achieve the primary ASO 'Contact'. All of the shake movements produced with the hands

437 were of the contact gesture shake hands rather than a hand only version of the non-

438 contact gesture arm shake (e.g. hand shake).

439

440 Thus, of the eight movements produced with one or more body parts, in five cases the

441 same primary ASO was achieved irrespective of body part used. In a further two cases,

442 the majority of body parts (particularly when grouped at the level of the fingers to arm)

443 produced the same primary ASO. In one case the primary ASO varied strikingly; and

444 here variation was seen not only in the body part but also in the gestural modality with

445 physical contact made in one but not the other. As a result the decision on whether or not

446 to lump body parts that were used was taken for each type of movement on a case-by-

447 case basis.

449 3.3.2 Does physical contact with the recipient modify the meaning of a gesture?

450 Outside of play, only the movements hit and shake were employed with both contact and

451 non-contact. The movement shake, as described above, includes both the non-contact arm

452 shake and the contact shake hands gestures. Shake with contact $(\mathrm{n}=9)$ achieved a primary

453 ASO of 'Contact' $(\mathrm{n}=7,78 \%)$; whereas shake without contact $(\mathrm{n}=3)$ achieved a primary

454 ASO of 'Follow' ( $\mathrm{n}=2,67 \%)$. The movement hit occurred in gestures such as punch

455 other, slap object, kick, stomp object, etc. Hit movements with contact ( $\mathrm{n}=134)$ achieved

456 a different primary ASO ('Follow', $\mathrm{n}=53,40 \%$ ) when compared to hit movements 
457 without contact ( $\mathrm{n}=40$; primary ASO 'Move away', $\mathrm{n}=13,33 \%)$. Three body parts

458 produced hit movements both with and without physical contact to the recipient: hand,

459 knuckles, and foot. In two cases the primary ASO achieved varied between the contact

460 and non-contact forms; however, of the 10/14 primary and secondary ASOs achieved

461 across the different body parts and levels of contact (Table 6) were a request for the

462 recipient to 'displace' themselves ('Follow', 'Move away', 'Move closer', 'Reposition'),

463 three were a request for 'Stop that', and one was for 'Sexual attention to a male'. As a

464 result, we suggest that it is appropriate to maintain the splitting of movements that lead to

465 contact with the recipient as opposed to an object, for example: hit other from hit object.

467 Table 6. Primary and secondary ASO of hit movements produced with and without 468 physical contact with recipient.

469

\begin{tabular}{|c|c|c|c|c|}
\hline $\begin{array}{l}\text { Move } \\
\text { ment }\end{array}$ & Body part & Modality & Primary ASO (\% of use) & Secondary ASO (\% of use) \\
\hline \multirow[t]{6}{*}{ Hit } & \multirow[t]{2}{*}{ Hand } & Contact & 'Follow' (44\%) & 'Move away' (30\%) \\
\hline & & Non contact & 'Stop that' $(65 \%)$ & 'Move away' (29) \\
\hline & \multirow[t]{2}{*}{ Knuckles } & Contact & 'Move away' (33\%) & $\begin{array}{l}\text { 'Follow'/‘Move } \\
\text { closer'/‘Sexual attention to } \\
\text { male' }(22 \%)\end{array}$ \\
\hline & & Non contact & 'Move away' (57\%) & 'Stop that' $(29 \%)$ \\
\hline & \multirow[t]{2}{*}{ Foot } & Contact & $\begin{array}{l}\text { 'Move away'/'Reposition' } \\
(50 \%)\end{array}$ & - \\
\hline & & Non contact & 'Stop that' $(40 \%)$ & 'Move away' (27\%) \\
\hline
\end{tabular}

471 3.3.3 Does the use of single or double-limb forms modify the meaning of a gesture?

472 Nineteen movements were performed with both single- and double-limb forms of the

473 same body part. Single-limb forms were more common across gestures types (single:

474 mean cases per movement $=98.3 \pm 109.6$; double: mean cases per movement $=28.2 \pm 45.9$;

475 paired t-test: $\mathrm{t}=3.86, \mathrm{df}=18, \mathrm{p}=0.0011)$. A greater proportion of the double-limb forms of 
476 the movements were used in play (proportion of single-limb forms in play: mean =

$4770.57 \pm 0.3$; proportion of double-limb forms in play: mean $=0.74 \pm 0.3$; Paired t-test:

$478 \mathrm{t}=2.63, \mathrm{df}=18, \mathrm{p}=0.0169)$.

479

480 Outside of play, seven movements included three or more cases of both the single- and

481 double-limb forms of the same body part employed towards a known ASO (Table 7). The

482 primary ASOs achieved were the same in the single- and double-limb forms of 6 of the 7

483 movements. We further compared the frequency with which this primary ASO was

484 achieved as compared to all other ASOs for the single and double limb forms and again

485 found no differences between them (Embrace + arm/arms, primary ASO = 'Contact',

486 Fisher's exact test $\mathrm{n}=30, \mathrm{p}=0.545$. Hit + foot/feet, primary ASO $=$ 'Follow', Fisher's

487 exact test $\mathrm{n}=41, \mathrm{p}=1.000$. Hit + hand/hands, primary ASO $=$ 'Follow', Fisher's exact test

$488 \mathrm{n}=97, \mathrm{p}=0.585$. Move object + hand/hands, primary ASO $=$ 'Follow', Fisher's exact test

$489 \mathrm{n}=63, \mathrm{p}=1.000$. Raise + arm/arms, primary ASO $=$ 'Acquire object', Fisher's exact test

$490 \mathrm{n}=27, \mathrm{p}=0.326$. Shake object + hand/hands, primary ASO $=$ 'Follow', Fisher's exact test

$491 \mathrm{n}=313, \mathrm{p}=0.443$ ). The seventh case (grab pull + hand/hands) only contained an $\mathrm{n}=16$

492 examples and showed no clear primary ASO in either single- or double-limb form (Table 493 7).

494

495 As a result, we suggest lumping single and double limb forms of the body parts used to

496 produce gesture movements: for example, the gesture arm raise will include both use of

497 single arm or double arms. 

movements. The proportion of gesture cases used to achieve an ASO is plotted for the same movement produced with a single-limb or double-limbs. ASOs with potentially similar meanings are plotted adjacent to each other. For clarity only ASOs for which the gesture was employed are labelled.
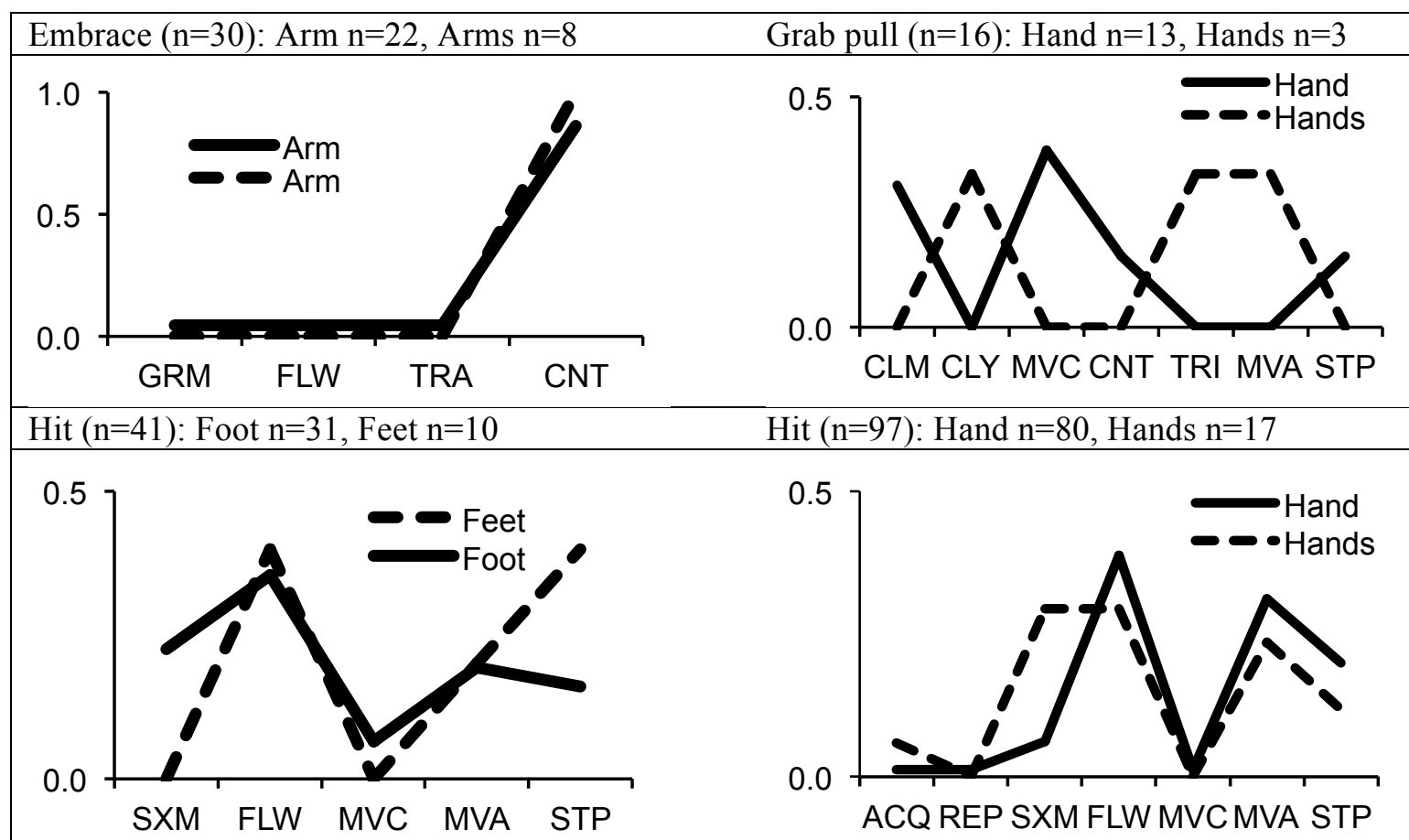

Hit ( $\mathrm{n}=97)$ : Hand $\mathrm{n}=80$, Hands $\mathrm{n}=17$

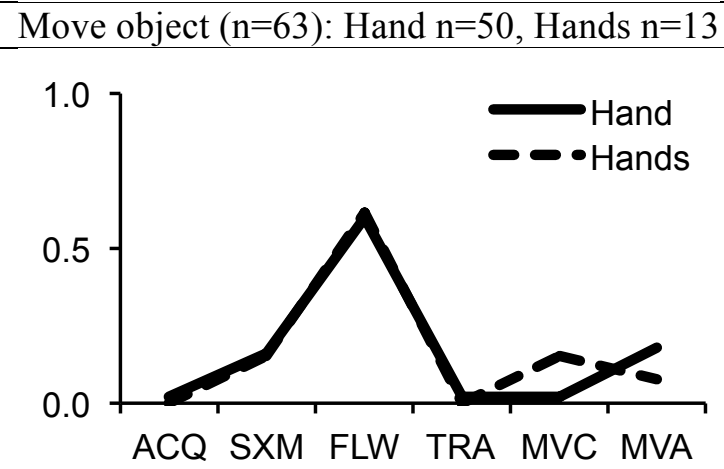

Raise (n=27): Arm $n=23$, Arms $n=4$

\begin{tabular}{|c|c|c|}
\hline Shake object $(n=328)$ : Hand $n=264$; Hands $n=64$ & ASO Key: & \\
\hline 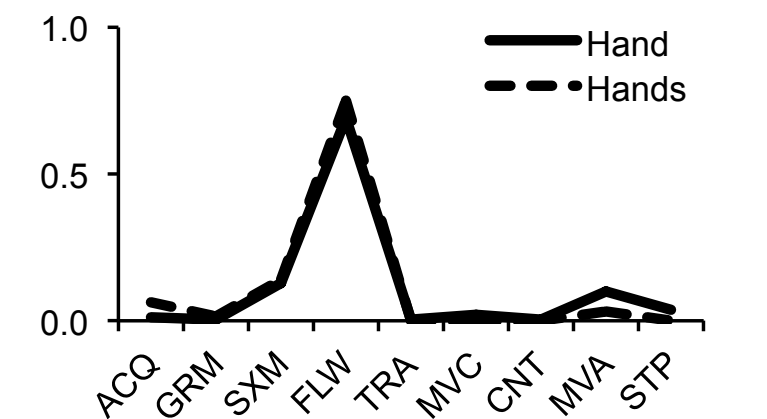 & $\begin{array}{l}\text { ACQ = Acquire } \\
\text { object } \\
\text { DIR = Direct } \\
\text { attention } \\
\text { GRM = Groom } \\
\text { REP = Reposition } \\
\text { CLM = Climb on me } \\
\text { CLY = Climb on you } \\
\text { SXM = Sexual } \\
\text { attention to male }\end{array}$ & $\begin{array}{l}\text { attention to female } \\
\text { FLW = Follow } \\
\text { TRA = Travel with } \\
\text { me - adult } \\
\text { MVC = Move closer } \\
\text { CNT = Contact } \\
\text { TRI = Travel with me } \\
\text { - infant } \\
\text { MVA = Move away } \\
\text { STP = Stop that }\end{array}$ \\
\hline
\end{tabular}




\subsubsection{Does the inclusion of an object modify the meaning of a gesture?}

506 Six movements were performed with the use of a detached object (hit, move object, shake

507 object, swing, tear off, throw). Only two movements were performed both with and

508 without object use: hit with the body part hand (with object $n=15$; without object $n=83$ )

509 and swing with the body part arm (with object $n=4$; without object $n=35$ ).

511 Outside of play, the primary ASO for hit with the hand without an object was 'Move

512 away' $(\mathrm{n}=29,35 \%)$, and with an object was 'Follow' $(\mathrm{n}=14,93 \%)$. The primary ASO for

513 swing with the arm both with $(n=4,100 \%)$ without an object $(n=20,57 \%)$ was 'Follow'

514 (Table 8). As a result, we suggest that it is appropriate to maintain splitting of movements

515 produced with and without detached objects, for example: hit other from hit with object.

Table 8. Distribution of ASOs in movements produced with and without a detached object. The proportion of gesture cases used to achieve an ASO is plotted for the same movement with and without a detached object. ASOs with potentially similar meanings are plotted adjacent to each other. $\mathrm{ACQ}=$ 'Acquire object'; REP = 'Reposition'; SXM = 'Sexual attention to male'; FLW = 'Follow'; MVC = 'Move closer'; MVA = 'Move away'; STP = 'Stop that'. For clarity only ASOs for which the gesture was employed are labelled.
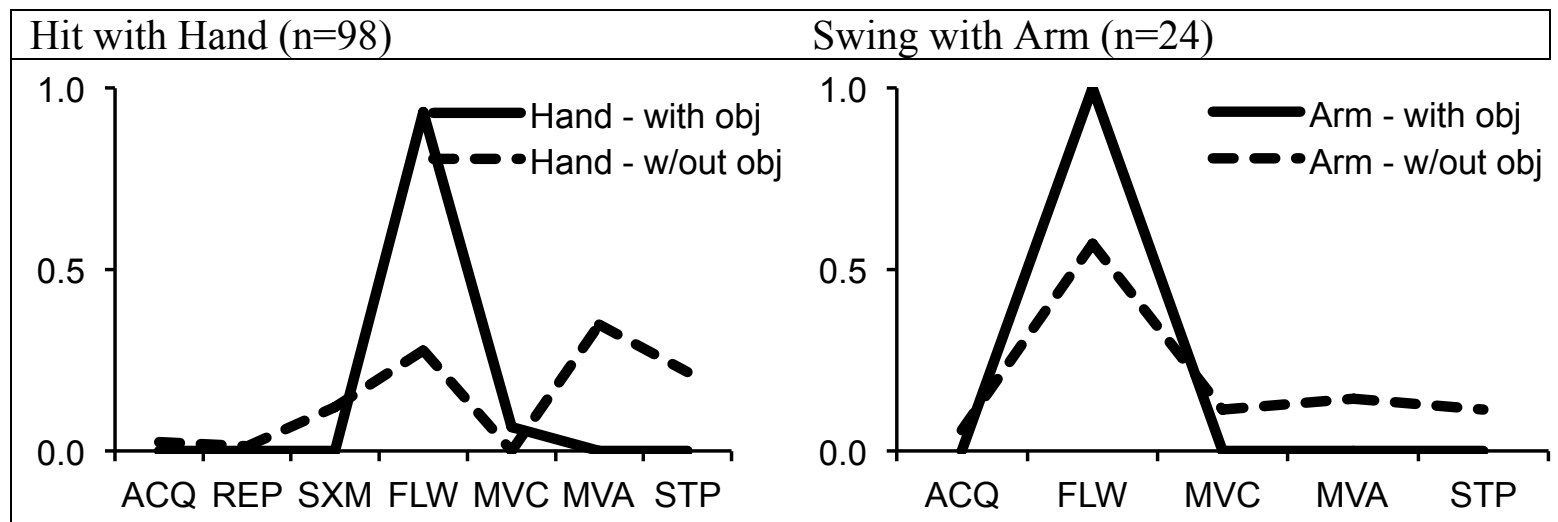


\section{3.3.5 Does the use of rhythmic repetition modify the meaning of a gesture?}

527 Twelve movements ( $\mathrm{n}=1227$ cases) were performed with rhythmic repetition; however,

528 the majority of rhythmic repetition cases $(\mathrm{n}=908,74 \%)$ were recorded in movements that

529 were only performed with repetition (rock, rub, scratch, shake, shake object, spin, stroke, 530 tear off, wave).

531

532 Outside of play, only two movements were employed with and without rhythmic

533 repetition. The movement dangle was used both with and without repetition; however,

534 only two cases were employed outside of play, one with and one without repetition. The

535 movement hit was used with the body parts foot and fingers with both repetition and non-

536 repetition of the movement (Table 9). We found differences in the primary ASOs for hit

537 with either the foot (with repetition = 'Stop that'; without repetition = 'Follow') or with

538 the fingers (with repetition $=$ 'Stop that'; without repetition $=$ 'Contact'). As a result, we

539 suggest maintaining the splitting of gestures that incorporate rhythmic repetition of the

540 movement, for example: the gestures tap and tapping.

541

542 
Table 9. Distribution of ASOs in movements produced with and without rhythmic

544 repetition. The proportion of gesture cases used to achieve an ASO is plotted for the

545 same movement with and without rhythmic repetition. ASOs with potentially similar

546 meanings are plotted adjacent to each other. $\mathrm{ACQ}=$ 'Acquire object'; $\mathrm{REP}=$

547 'Reposition'; MVC = 'Move closer'; CNT = 'Contact'; MVA = 'Move away'; STP =

548 'Stop that'. For clarity only ASOs for which the gesture was employed are labelled.

Hit with Foot: with repetition $\mathrm{n}=16 ; \quad$ Hit with Fingers: with repetition $\mathrm{n}=5$; without repetition $\mathrm{n}=25$ without repetition $\mathrm{n}=14$

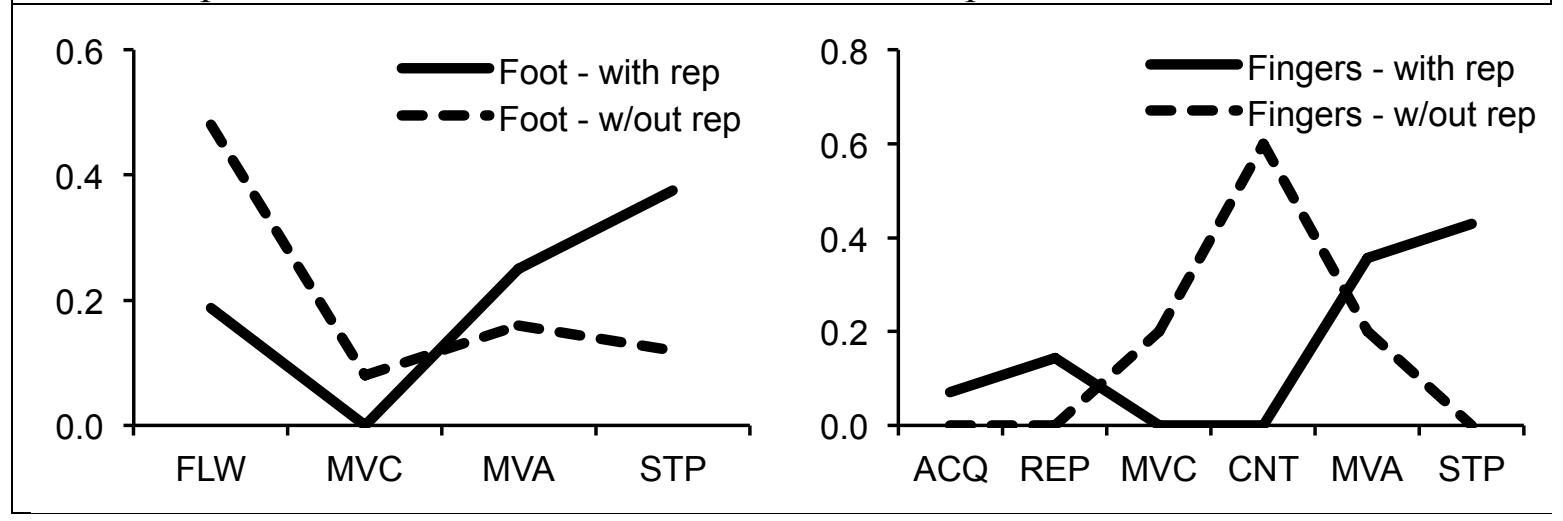

$552 \quad 3.4$ Revising the catalogue of meaningful gestures for the chimpanzee

553 To summarize, our analysis of the appropriate categorization of chimpanzee gestures,

554 based on the intended meanings of gestures, has the following consequences:

1 No effect of simultaneous as opposed to alternating hit movements

Outcome Lump gesture types previously split e.g. drum with slap/punch multiple 2hands

2 No effect of body position on spin movements

Outcome Lump gesture types previously split e.g. pirouette, side roulade, somersault

\section{Deictic gestures}

Outcome Allow for the coding of gesture types as deictic depending on the signaller and recipient's movements.

4 Body part impacts meaning of some movements but not others

Outcome Lump body parts: fingers and hand 
Lump gestures arm swing and leg swing

Lump gestures slap, punch as new gesture hit

\section{Physical contact with recipient impacts meaning of movement}

Outcome Maintain split of movements on other versus on object

6 Use of single- or double-limb forms impacts meaning of some movements

Outcome Lump forms for movements: embrace, move object, raise, shake object

Maintain split form for movements hit and grab-pull

\section{Inclusion of object impacts meaning of movements}

Outcome Maintain split of with/without object movement forms

\section{Repetition of movement impacts meaning of hit movements}

Outcome Include splitting of single versus repeated hit movements

556 From this we generated a new standard St Andrews Catalogue for chimpanzee gestural

557 communication, containing 81 gesture types (Table S1). In this catalogue, all gestures

558 were distinguished based on the features for which there is evidence that they affect the

559 primary meaning of the gesture. We suggest that gestures that are used to indicate

560 (directed reach) that have the same physical form as gestures that are not used to indicate

561 (reach) be considered to be the same type of gesture, but one that can be employed with

562 or without an additional, non-physical, feature of deixis.

\section{4. Discussion}

566 Considerable importance has been attached to the discovery of the large overlap between

567 the lists of gestures described for the different great ape populations, suggesting a

568 predominantly species - and even family - typical origin (Hobaiter \& Byrne, 2011a). One

569 weakness of these claims is that commonality in gestures might simply result from a 
570 limited possible range of movements. Here we see that any such limitation is far from the

571 case: the potential repertoire of physically possible combinations of the features extends

572 to over a thousand types, of which only $12 \%$ are employed by chimpanzees in their

573 gesturing.

575 Interestingly, from the perspective of a gestural theory of language evolution, a repertoire

576 of a thousand signals would be (more than) sufficient for productive language. The

577 original dictionary for Esperanto, for example, has around 900 root words (Zamenhof,

578 1905); while 'mother-in-law' languages (for example: Dyalyuy used by Dyirbal speakers

579 to communicate in the presence of relatives with whom there is a speech taboo) contain

580 only a few hundred items (Dixon, 1972). The upper limit on the size of the chimpanzee

581 gestural repertoire is clearly not set by the features used to distinguish among different

582 gestures, and in a species that needed - and was capable of envisioning - an extended

583 repertoire that could serve as a language there would be no need to change from a manual

584 system of gesture in order to achieve it.

586 Building on previous morphological classifications of limb and hand movements in ape

587 gesture (e.g. Forrester, 2008 and Roberts et al., 2012) we have taken a systematic

588 approach to the chimpanzee gestural repertoire, employing six core features to

589 discriminate all gesture types at the same level of classification. We then re-examined the

590 catalogue produced taking into account the meanings for which the chimpanzee signallers

591 employ these gestures. In doing so we were able to confirm the importance of

592 categorizing by features such as the use of detached objects, and the use of rhythmic 
593 repetition; conversely, we were able to simplify the categorization scheme by discarding

594 features that chimpanzee signallers did not use, for example the use of single- or double-

595 limb forms across the majority of movements, and the use of simultaneous versus

596 alternating hitting movements. Further empirical research is required to investigate

597 gesture use across great ape communities and species, but we suggest that the use of

598 meaning to classify gestures within great ape repertoires provides a powerful new tool for

599 studies of great ape communication.

600

601 We have noted a small number of gestures that are used deictically (present; push; reach;

602 swing), to indicate specific places, such that only when the recipient takes account of

603 those places in its response is the signaller satisfied. (In contrast, with a gesture like fling,

604 while it is necessarily directional in motion and requires a movement on the part of the

605 recipient, the specific direction is not part of its interpretation: 'Move anywhere that's

606 away from me' rather than 'Move away to there'.) The location in effect functions as an

607 "empty slot" in the specification of the gesture. In previous attempts to describe the

608 chimpanzee repertoire (e.g. Hobaiter \& Byrne, 2011a; Hobaiter et al., 2013) we

609 distinguished some gestures in which the location was always critical (treating directed

610 push and push as separate gesture types), whereas in others (arm swing) its presence was

611 optional. In the present review, we have distinguished gestures based on their physical

612 features, and since the number of locations that can be indicated is, technically speaking,

613 infinite, we could not use the location as part of the gesture classification system. Instead,

614 we have coded a binary indication of deixis separately within a gesture type (e.g. push:

615 directed = yes/no; swing: directed $=$ yes/no). 
617 Finding only a small number of deictic gestures is not greatly at variance with human

618 communication, in which direction can be indicated by index-finger pointing, head

619 movement, and in some cultures, lip pointing. As with these human gestures, a

620 chimpanzee gesture may be employed with or without deixis. The physical form of a

621 chimpanzee reach palm gesture that is used in dyadic communication to beg for the food

622 that the recipient is holding is the same as the physical form of a chimpanzee reach palm

623 that is used in triadic communication to indicate another individual or object (Hobaiter et

624 al., 2012). These are distinguished not by physical form but by accompanying behaviour,

625 such as apparently ostensive gaze and head movements. In the same way, in human

626 communication an identical head movement, nod, may be used in dyadic communication

627 as agreement, or in triadic communication to indicate a location to the recipient, for

628 example where the signaller has their hands full. Although deixis functions referentially,

629 indicating external entities by directional pointing, the referent itself is not encoded in the

630 signal, as is the case with the words of language or symbolic gestures. Thus, in the case

631 of a word in a language, for instance, a word can indicate - "point to" - its referent even

632 when that is not physically present (e.g. the cake in the shop), or is abstract in nature (e.g.

633 next Wednesday). Nevertheless, the possibility that deixis may over evolutionary time

634 have been the root from which reference developed makes these few instances of

635 particular interest.

636

637 The approach to defining gesture types that we offer is flexible, and could be employed to 638 describe gesture types in all great ape species. Extending this approach to new species 
639 and sub-species may reveal new gesture types. If so, the current catalogue can be easily

640 extended through the description of new movements, new movement + body part

641 combinations, or the addition of single/double limb distinctions, detached objects,

642 contact, rhythmic repetition, or deixis to existing ones. Crucially, using the reactions of

643 signallers, to identify gestures that were intended to be different by the apes themselves,

644 may allow a more appropriate categorization of signals - from an ape's perspective;

645 offering us new means to investigate the evolutionary origins of linguistic features such

646 as syntactic structure or reference.

647

648

649 5. Acknowledgments

650 We thank all the staff of the Budongo Conservation Field Station. For permission to work

651 in Uganda, we thank the Uganda National Council for Science and Technology, the

652 Presidents Office, the Uganda Wildlife Authority and the Uganda Forestry Authority.

653 Fieldwork of $\mathrm{CH}$ was generously supported by the Wenner Gren Foundation, the Russel

654 Trust, and the British Academy.

655

656

657 6. References

658 Altmann, J., 1974. Observational study of behaviour: sample methods: Behav. 49, 227-265.

659 Bateson, G., 1971. A theory of play and fantasy. In: Steps to an ecology of mind. New York:

660 Ballantine Books (Original work published 1955), pp177-193. 
661 Bekoff, M., \& Byres, J. A., 1981. Social play: Structure, function, and the evolution of a 662 cooperative social behavior. Eds. Burghardt, G. M., Bekoff, M. The development of

663 behavior, Comparative and evolutionary aspects. New York: Garland STPM Press, 664 pp367-383.

665 Cartmill, E.A., Byrne, R.W., 2007. Orangutans modify their gestural signalling according 666 to their audience's comprehension. Curr. Biol. 17, 1345-1348.

667 Cartmill, E.A., Byrne, R.W., 2010. Semantics of primate gestures: intentional meanings 668 of orang-utan gestures. Anim. Cogn. 13, 793-804.

669 Cäsar, C., Zuberbühler, K., Young, R.J., Byrne, R.W., 2013. Titi monkey call sequences

670 vary with predator location and type. Biol. Lett. doi:10.1098/rsbl2013.0535

671 Dennett, D.C., 1987. The intentional stance. Cambridge, MA: MIT Press.

672 Dixon, R.M.W., 1972. The Dyirbal language of north Queensland. Cambridge Studies in 673 Linguistics. Vol 9. CUP Achive.

674 Eggling, W.J., 1947. Observations on the ecology of the Budongo Rain Forest, Uganda. J. 675 Ecol. 34, 20-87.

676 Forrester, G.S., 2008. A multidimensional approach to investigations of behaviour:

677 revealing structure in animal communication signals. Anim. Behav. 76, 1749-1760.

678 Frohlich, M., Wittig, R.M., Pika, S., 2016. Should I stay or should I go? Initiation of joint 679 travel in mother-infant dyads of two chimpanzee communities in the wild. Anim. Cogn. $680 \quad 19,483-500$.

681 Genty, E. Breuer, T., Hobaiter, C., Byrne, R.W., 2009. Gestural communication of the 682 gorilla (Gorilla gorilla): repertoire, intentionality and possible origins. Anim. Cogn. 12, $683 \quad 527-546$. 
684 Graham, K., Furuichi, T., Byrne, R.W., 2016. Gestural repertoire of the wild bonobo (Pan 685 paniscus): a mutually understood communication. Anim. Cogn. Doi:10.1007/s10071-016$686 \quad 1035-9$.

687 Grice, H.P., 1957. Meaning. Phil. Review. 66, 377-388.

688 Goodall, J., 1968. The chimpanzees of Gombe: patterns of behaviour. Harvard University

689 Press, Cambridge.

690 Gupta, S., Sinha, A., 2016. Not here, there! Possible referential gesturing during

691 allogrooming by wild bonnet macaques, Macaca radiata. Anim. Cogn. 19, 1243-1248.

692 Halina, M., Rossano, F., Tomasello, M., 2013. The ontogenetic ritualization of bonobo

693 gestures. Anim. Cogn. 16, 653-666.

694 Hobaiter, C., Byrne, R.W., 2010. Able-bodied wild chimpanzees imitate a motor

695 procedure used by a disabled individual to overcome handicap. PLoS One. 5, e11959.

696 Hobaiter, C., Byrne, R.W., 2011a. The gestural repertoire of the wild chimpanzee. Anim.

697 Cogn. 14, 745-767.

698 Hobaiter, C., Byrne, R.W., 2011b. Serial gesturing by wild chimpanzees: its nature and

699 function for communication. Anim. Cogn. 14, 827-838.

700 Hobaiter, C., Byrne, R.W., 2012. Gesture use in consortship. Eds Pika, S., Liebal, K.,

701 Developments in Primate Gesture Research. John Benjamins. pp129-146.

702 Hobaiter, C., Byrne, R.W., 2014. The meaning of chimpanzee gestures. Curr. Biol. 24,

$703 \quad 1596-1600$.

704 Hobaiter, C., Leavens, D.A., Byrne, R.W., 2013. Deictic gesturing in wild chimpanzees,

705 (Pan troglodytes)? Some possible cases. J. Comp. Psychol. 128, 82-89. 
706 Leavens, D.L., Hopkins, W.D., Bard, K.A., 1996. Indexical and referential pointing in

707 chimpanzees (Pan troglodytes). J. Comp. Psychol. 110, 346.

708 Leavens, D.L., Hopkins, W.D., 1998. Intentional communication by chimpanzees: a

709 cross-sectional study of the use of referential gestures. Dev. Psychol. 34, 813.

710 Leavens, D.L., Russell, J.L., Hopkins, W.D., 2010. Multimodal communication by

711 captive chimpanzees (Pan troglodytes). Anim. Cogn. 13, 33-44.

712 Liebal, K., Pika, S., Tomasello, M., 2006. Gestural communication of orang-utans

713 (Pongo pygmaeus). Gesture. 6, 1-38.

714 Moore, R., 2016. Meaning and ostenstion in great ape gestural communication. Anim.

715 Cogn. 19, 223-231.

716 Nishida, T., 1980. The leaf-clipping display: a newly-discovered gesture in wild

717 chimpanzees. J. Hum. Evol. 9, 117-128.

718 Pika, S., Liebal, K., Tomasello, M., 2003. Gestural communication in young gorillas

719 (Gorilla gorilla): gestural repertoire, learning, and use. Am. J. Primatol. 60, 95-111.

720 Pika, S., Liebal, K., Tomasello, M., 2005. Gestural communication in subadult bonobos

721 (Pan paniscus): repertoire and use. Am. J. Primatol. 65, 39-61.

722 Plooij, F.X., 1978. The behavioral development of free-living chimpanzee babies and

723 infants. Ablex Publishing Corporation, Norwood.

724 Pollick, A.S., De Waal, F.B.M., 2007. Ape gestures and language evolution. Proc. Natl.

725 Acad. Sci. 104, 8184-8189.

726 Quiatt, D., Reynolds, V., Stokes, E.J., 2002. Snare injuries to chimpanzees (Pan

727 troglodytes) at 10 study sites in east and west Africa. Afr. J. Ecol. 40, 303-305. 
728 Roberts, A.I., Vick, S.J., Roberts, S.G.B., Buchanan-Smith, H.M., Zuberbühler, K. 2012.

729 A structure-based repertoire of manual gestures in wild chimpanzees: Statistical analyses

730 of a graded communication system. Evol. Hum. Behav. 33, 578-589.

731 Roberts, A.I., Roberts, S.G.B., Vick S.-J., 2014. The repertoire and intentionality of

732 gestural communication in wild chimpanzees. Anim. Cogn. 17, 317-336.

733 Schaller, G.E., 1963. The mountain gorilla: Ecology and behavior. University of Chicago

734 Press.

735 Schlenker, P., Chemla, E., Arnold, K., Zuberbühler, K., 2016a. Pyow-hack revisited: Two

736 analyses of Putty-nosed monkey alarm calls. Lingua. 171, 1-23.

737 Schlenker, P., Chemla, E., Casar, C., Ryder, R., Zuberbühler, K., 2016b. Titi semantics:

738 context and meaning in Titi monkey call sequences. Nat. Lang. Linguist. Theory.

739 doi:10.1007/s11049-016-9337-9

740 Scott-Phillips, T., 2015. Meaning in animal and human communication. Anim. Cogn.

$741 \quad 18,801-805$.

742 Scott-Phillips, T., 2016. Meaning in great ape communication: summarising the

743 debate. Anim. Cogn. 19, 233-238.

744 Seyfarth, R.M., Cheney, D.L. 2003. Signalers and receivers in animal communication.

745 Ann. Rev. Psychol. 54, 145-173.

746 Stokes, E.J., Byrne, R.W., 2001. Cognitive capacities for behavioural flexibility in wild

747 chimpanzees (Pan troglodytes): the effect of snare injury on complex manual food

748 processing. Anim. Cogn. 4, 11-28.

749 Tanner, J.E., Byrne, R.W., 1996. Representation of action through iconic gesture in a

750 captive lowland gorilla. Curr. Anthropol. 37, 162-173. 
751 Tomasello, M., George, B., Kruger, A., Farrar, J., Evans, E., 1985. The development of

752 gestural communication in young chimpanzees. J. Hum. Evol. 14, 175-186.

753 Tomasello, M., Gust, D., Frost, T.A., 1989. A longitudinal investigation of gestural

754 communication in young chimpanzees. Primates. 30, 35-50.

755 Tomasello, M., Call, J. Nagell, C., Olguin, R., Carpenter, M., 1994. The learning and use

756 of gestural signals by young chimpanzees: a trans-generational study. Primates. 35, 137-

757154.

758 Vail, A.L., Manica, A., Bshary, R., 2013. Referential gestures in fish collaborative

759 hunting. Nat. Commun. 4, 1765.

760 Zamenhof, L.L., 1905. Fundamento de Esperanto. 